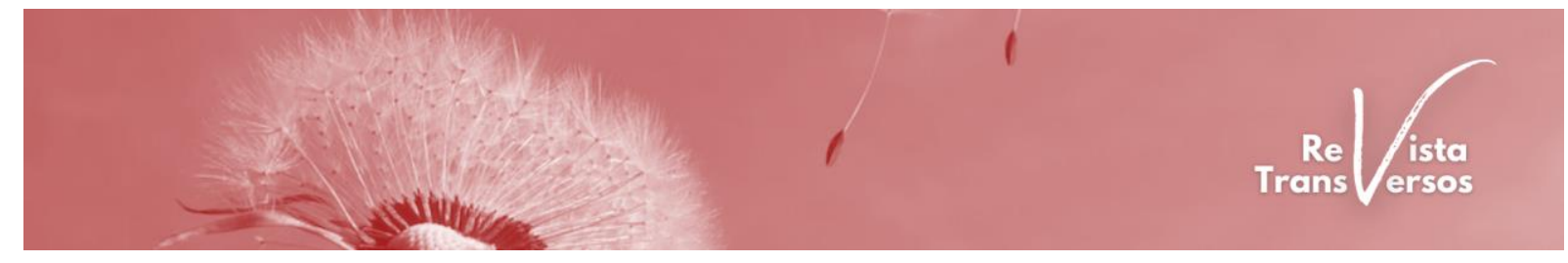

DOI: $10.12957 /$ transversos.2021.62746

\title{
APRENDIZAGEM ESCOLAR DE HISTÓRIA EM TEMPOS DE PANDEMIA NO CAP/UERJ: UM OLHAR DIDÁTICO-HISTÓRICO SOBRE O TEMPO PRESENTE ${ }^{1}$ \\ SCHOOL LEARNING OF HISTORY IN TIMES OF PANDEMIC AT CAP-UERJ: A DIDACTIC-HISTORICAL LOOK AT THE PRESENT TIME
}

\author{
Giselle Pereira Nicolau \\ Cap-UERJ \\ giselle.histoire@gmail.com \\ Vivian Zampa \\ CAp-UERJ \\ Universidade Salgado de Oliveira (UNIVERSO) \\ vivianzampa@hotmail.com \\ Sonia Maria Wanderley \\ CAp-UERJ \\ Universidade do Estado do Rio de Janeiro (UERJ) \\ soniamaiw@gmail.com
}

\footnotetext{
${ }^{1}$ As reflexões apresentadas fazem parte do projeto de pesquisa Cultura História e Ensino de História: Interseções com a História Pública, relacionado ao Laboratório de Ensino de História (CAp/UERJ) e ao Laboratório de Estudos das Diferenças e Desigualdades (LEDDES/UERJ).
} 
Resumo:

A realidade escolar foi diretamente abalada pela pandemia de Covid-19, considerando os sucessivos meses de confinamento, a ausência do contato presencial entre alunos e professores, o medo da infecção e, para muitos, a ausência de um espaço e de condições técnicas apropriadas para estudar (DIAS; PINTO, 2020). A partir desse contexto e considerando um lugar específico - o Colégio de Aplicação da UERJ, o presente texto apresenta e discute a proposta didática desenvolvida pela equipe de História desse Instituto, buscando problematizar o sentido de ensinar e aprender história em um momento de rupturas cognitivas e afetivas como o vivenciado. O diálogo se desenvolve a partir do que é denominado um exercício didáticohistórico (RÜSEN, 2010a) que insere o processo do ensino-aprendizagem de história escolar no caldo cultural formado pela cultura histórica contemporânea.

Palavras-chave: Aprendizagem; didática da História; cultura histórica; tempo presente.

\begin{abstract}
The school reality was directly shaken by the Covid-19 pandemic, considering the successive months of confinement, the absence of face-to-face contact between students and teachers, the fear of infection and, for many, the absence of an appropriate space and technical conditions for studying. (DIAS, PINTO, 2020). From this context and considering a specific place - the College of Application of UERJ, this text presents and discusses the didactic proposal developed by the History team of this Institute, seeking to problematize the meaning of teaching and learning History in a moment of cognitive disruptions and affective as the experienced. The dialogue develops from the debate about what we call a didactic-historical exercise (RÜSEN, 2010a) that inserts the teachinglearning process of school history in the cultural broth formed by contemporary historical culture.
\end{abstract}

Keywords: Learning; History didactics; historical culture; present tense.

\section{Introdução}

A realidade escolar foi profundamente abalada pela pandemia de Covid-19. Nesta dimensão, números apresentados pela UNESCO (2020) indicam que mais de $90 \%$ dos estudantes do mundo, da educação infantil ao ensino superior, foram atingidos pelos seus impactos, considerando os sucessivos meses de confinamento, a ausência do contato presencial com os colegas da escola, o medo da infecção e, para muitos, a ausência de um espaço e de condições técnicas apropriadas para estudar. (DIAS; PINTO, 2020)

No Rio de Janeiro, a suspensão das aulas a partir do decreto de 16 de março de 2020, inicialmente por 15 dias, seguida pela recomendação do uso de plataformas digitais para o ensino remoto, trouxe uma série de dúvidas e inquietações aos professores das redes pública e privada.

No caso específico do Instituto de Aplicação Fernando Rodrigues da Silveira (CAp/Uerj), as discussões perpassaram a necessidade imediata de reflexões em meio à experiência 
traumática da morte de milhares de pessoas. Neste cenário, e diante de uma certa pressão para o início das atividades via ensino remoto, um significativo número de professores questionou se era correto manter aulas virtuais e atividades pedagógicas remotas com o sentido de normalidade, diante de um momento singular de incertezas e de esgotamento mental de docentes e discentes.

Esse questionamento veio acompanhado da proposição de que, antes do início da retomada das aulas, seria necessário repensar a própria instituição e o que poderia ser entendido como atividades pedagógicas adequadas naquele momento. Com a questão colocada e aceita, realizaram-se reuniões pela comunidade escolar que elencaram um conjunto de particularidades do Colégio. O CAp/Uerj é um Instituto da Universidade do Estado do Rio de Janeiro (UERJ), que atua nos campos de Ensino, Pesquisa e Extensão, constituindo um espaço específico de estágio para os cursos de licenciatura da UERJ, campus Maracanã. Com essa composição, o colégio volta-se tanto à Educação Básica, quanto à oferta de disciplinas nos cursos de licenciatura, além de abrigar o Programa de Pós-graduação em Ensino de Educação Básica (PPGEB), com um mestrado profissional. Deste modo, por se tratar de um colégio reconhecido pela promoção da educação básica de qualidade e por um corpo docente qualificado, ele tem considerável procura e atrai muitos alunos em seus processos seletivos.

Esta procura diferenciada se traduz em uma composição de discentes oriundos de diferentes regiões do Rio de Janeiro, que vão da área central, próxima a localização do CAp, até a zona norte, oeste, baixada fluminense, Niterói, São Gonçalo e região serrana. Tão heterogêneo quanto o local de residência dos alunos é a sua realidade socioeconômica, considerando que, enquanto alguns se encaixam nos padrões de classe média e classe média alta, outros vivem em condições extremante precárias, recebendo o auxílio de bolsas de estudo para que possam garantir condições mínimas para permanecer na escola.

Atentos a esta realidade, algumas preocupações iniciais foram postas: quantos alunos teriam efetivamente condições de acompanhar as atividades via ensino remoto? Possuiriam eles conexão de internet, computadores e celulares adequados? Possuiriam, ainda, um local apropriado para as atividades a distância?

$\mathrm{Na}$ sequência das problemáticas discutidas em reuniões e plenárias on line foram realizadas ações de contato com os discentes e busca de informações objetivas, voltadas ao mapeamento das condições gerais para a sua inserção no modelo de ensino remoto então proposto. 
Concomitante a essas ações, setores administrativos apontavam as pressões interna e externa para o início de atividades pedagógicas de forma remota, considerando que as redes privada e pública já haviam iniciado experiências semelhantes e, sobretudo, que o CAp detinha há alguns anos uma plataforma de ensino remoto, o AVACAp (Ambiente Virtual de Aprendizagem do Instituto de Aplicação Fernando Rodrigues da Silveira)², que já era utilizada por alguns professores da escola.

Após inúmeros debates entre docentes, direção, responsáveis pelos estudantes e a Associação de Docentes da UERJ (ASDUERJ), alinhados às discussões e às resoluções indicadas por essa Universidade, iniciou-se o plano de retomada das atividades escolares, com a implementação de um calendário gradual, considerando o levantamento e o fornecimento de recursos (celulares e planos de internet) para todos os alunos e professores com dificuldade de acesso às atividades remotas. Assim, entre finais de maio e junho de 2020, iniciou-se a primeira fase das atividades acadêmicas, acomodadas ao universo não presencial, e, no caso do CAp, à autonomia de planejamento de seus diferentes departamentos e áreas.

\section{Construindo caminhos em tempos incertos}

Em meio aos primeiros desafios impostos ao ensino em tempos de pandemia, a equipe de professores de História ${ }^{3}$, que pertence ao Departamento de Ciências Humanas e Filosofia (DCHF), realizou encontros nos quais foram discutidos tanto os diferentes levantamentos realizados pela escola - sobre as necessidades econômicas dos alunos e suas famílias e a existência ou inexistência de equipamentos, conexão e espaços apropriados aos estudos, dentre outros -, quanto a necessidade de uma adaptação do planejamento pedagógico da disciplina aos campos da educação e da própria área naquele momento. Deste modo, problematizações sobre currículo, metodologia, e o sentido do ensino-aprendizagem da disciplina escolar História em um contexto completamente diferenciado pautaram as ações do grupo a partir de algumas inquietações: como

\footnotetext{
${ }^{2} \mathrm{O}$ Ambiente Virtual de Aprendizagem do Instituto de Aplicação Fernando Rodrigues da Silveira foi desenvolvido a partir de uma parceria intrainstitucional, iniciada em 2015, entre o Laboratório de Tecnologias de Informação e Comunicação (LaTIC/Uerj) e o Laboratório de Ensino Leonardo da Vinci (LEDEN), vinculado ao CAp/Uerj, sendo o último responsável pelo design e pela administração do ambiente. Cf.: RIBEIRO, Andrea da Silva Marques; OLIVEIRA, Esequiel Rodrigues; MELO, Rodrigo Fortes. AVA e Ensino Híbrido: da Educação Básica à Formação Docente. Revista Tecnologia E Cultura, Rio de Janeiro, N. 32, Ano 21, jul./dez. 2018 - p. 22.

${ }^{3}$ A equipe de História que lecionava em turmas da Educação Básica no CAp, neste período, era composta pelos professores: Alcidesio de Oliveira Júnior; Andrea Galúcio; Giselle Nicolau; Helena Araújo; Hilton Meliande; José Roberto da Silva; Larissa Costard; Leonardo Padilha; Moema Alves; Vivian Zampa; e William Vaz.
} 
trabalhar a disciplina remotamente, em um padrão de "normalidade", deslocado do sentido urgente que o presente apontava?

Seguindo o entendimento de que o ensino de História se relaciona a muitas possibilidades, ligadas a diferentes concepções e usos sociais (CERRI, 2009: p. 150), houve um consenso quanto a se deslocar da concepção tradicionalmente trabalhada nos programas do ensino básico, que, de maneira geral, engloba:

- O privilegiamento da ordem cronológica dos conteúdos, da sua linearidade.

- Seleção de conteúdos sintonizada a uma visão de mundo europeu (...)

- Perspectiva memorista, no sentido de afetiva, identificadora, que aparece aos sujeitos como se fosse natural, decorrente do viver, em vez de aparecer como construção.

- História a partir das elites ou do que elas reconhecem como histórico. (CERRI, 2009: p. 152).

De forma a romper com essa perspectiva, o tempo presente foi considerado um ponto de partida para o desenvolvimento da proposta da equipe. Os recortes temáticos privilegiados referenciavam questões e problemas do tempo presente que, problematizados pelos docentes a partir das possibilidades etárias e dos grupos escolares, buscavam contemplar o desenvolvimento do pensamento histórico ou a consciência histórica - compreendida como a capacidade humana de atribuir sentido à vida no tempo. (LIMA, 2014: p. 61).

Objeto de intensos debates pela historiografia e pelo ensino de história há décadas (FERREIRA, 2000), o estudo do tempo presente vem cada vez mais afastando a lógica de que a falta de distanciamento no tempo pode ser um empecilho para o entendimento da realidade analisada, de forma a apontar para uma série de procedimentos teóricos e metodológicos, que confirmam o rigor e a importância deste campo. Além disso, conforme aponta Marieta de Moraes Ferreira “(...) o estudo da presença do passado incorporada ao presente das sociedades, iniciado pelos historiadores do tempo presente, abre novas temáticas e abordagens para pesquisadores de outros períodos da história” (2000: p. 10).

Uma vez delimitado este recorte, partiu-se para a observação de questões ligadas ao universo da História, que se apresentavam de forma mais recorrente para alunos, professores e seus ambientes de convívio. Questões essas permeadas por informações vinculadas pelas diferentes mídias. Neste processo, se milhares de vida ceifadas pela Covid-19 constituíam a pauta principal, a escalada crescente do conservadorismo, do negacionismo e de ações não democráticas a acompanhavam.

De forma pontual, a morte de George Floyd, homem negro de 46 anos, após detenção policial, imobilização e asfixia pela polícia local na cidade norte-americana de Minneapolis, 
ganhou espaço nas diferentes mídias no final de maio de 2020. Esta ação sensibilizou inúmeros grupos, que a colocaram em debate, considerando a forma covarde e truculenta como "Um dos policiais, que é branco, ajoelhou sobre o pescoço de Floyd e, com as mãos nos bolsos, posava para as câmaras de celular que filmavam Floyd agonizando e implorando pela mãe e por ar. As últimas palavras de Floyd foram: 'Eu não consigo respirar!’ (PINHA; SOTENOS, 2020).

No bojo dessa discussão, e diante dos protestos antirracistas realizados nos Estados Unidos e em inúmeros outros países incluindo o Brasil - intensamente noticiados pela imprensa -, a temática do racismo foi considerada fundamental para o início da retomada das atividades escolares na disciplina História.

Assim, colocava-se, de modo prático, a possibilidade de pensar o ensino e a aprendizagem de forma mais ampla e ligada à cultura histórica. De acordo com Jorn Rüsen, a cultura histórica relaciona-se às narrativas e aos sentidos que buscam orientar o homem no tempo, produzidas por um conjunto extenso e diferenciado de instituições sociais - tais como a escola, os órgãos de administração pública, os meios de comunicação e as instituições culturais -, que integram “(...) funções de ensino, entretenimento, legitimação, crítica, distração, ilustração e outras formas de lembrar" (RÜSEN, 1994: p 2-3). Logo, segundo esta perspectiva, o contato com a História, para além da escola, acontece por meio de experiências sociais distintas que nem sempre estão pautadas por um conhecimento produzido a partir da metódica científica.

O caso Floyd abriu espaço para uma gama de temáticas sensíveis ligadas à trajetória do racismo, do antirracismo e do autoritarismo, que contribuíram para a sua projeção na cultura histórica contemporânea. Esta constatação motivou ainda mais os professores a pensar nestes recortes para o retorno das atividades pedagógicas no CAp, de forma a valorizar o saber escolar, como parte dessa cultura histórica e da ressignificação dos saberes que a compõe.

Delimitada essa primeira escolha, optou-se pelo trabalho coletivo dos professores, dividido, de forma não rígida, por grupos. A saber: sexto e sétimo ano, oitavo e nono ano e ensino médio. A proposta geral da disciplina foi disponibilizada aos alunos e responsáveis por meio de uma carta redigida em conjunto pelos docentes da área na qual foi afirmado que:

Considerando os fundamentos desta disciplina social e humanista e após muitas reuniões pedagógicas ao longo dos últimos meses, os professores de História iniciarão a realização de atividades planejadas, que preservam o objetivo principal de ensinar História na escola (aprender a pensar historicamente), e que também nos ajudam a entender o momento histórico que estamos vivendo, com interrogações enormes e muito urgentes. (COSTARD et al., 2000) 
Nesta carta fora indicado, ainda, que as orientações de atividades, incluindo encontros síncronos e assíncronos, seriam disponibilizadas regularmente nas salas do AVACAp. E que, além delas, constituir-se-ia o "Espaço Aberto de História" com a indicação de livros, artigos e filmes, em constante atualização, de acesso livre. Por outro lado, também fora organizado um outro canal de postagens e de interação ligado à disciplina no Instagram, com vistas a outras formas de aproximação, bem como de adequação ao cotidiano dos alunos.

A organização dos professores em grupos de trabalho levou a elaboração de diferentes atividades no formato síncrono e assíncrono, com o objetivo de compreender como o racismo, enquanto um processo histórico, foi construído nas dimensões econômica, política, social e subjetiva. Respeitando a faixa-etária e a adequação da abordagem e discussão do tema em cada um dos grupos, foram organizados debates, roteiros de leitura, estudos dirigidos, e atividades fomentadas por filmes, literatura e fontes específicas.

Estas ações tomavam como princípio a compreensão de que o processo de ensino e aprendizagem histórico deve ser estimulado “(...) a partir de experiências e ações relevantes do presente" (RÜSEN, 2010: p. 44). Dimensão que reforçava o entendimento, ainda segundo Rüsen (2010: p. 44), de que a História passa a ter um sentido prático na vida dos alunos, apenas quando deixa de ser apenas estudada como uma mera assimilação de um bloco de conhecimentos positivos, e passa a ser construída a partir de problemáticas, discussões e da proposição de respostas.

Nesta perspectiva, uma das propostas pedagógicas desenvolvidas para o oitavo e nono ano e para o ensino médio ligou-se à discussão do conceito de racismo e da noção disputa de memória. Fomentadas, para além do caso Floyd, por questões do momento ligadas à derrubada de monumentos e estátuas associadas à escravidão, ao colonialismo e ao racismo na Europa e nos Estados Unidos (LEAL, 2020), assim como, de outro lado, no Brasil, à ordem de remoção de biografias de sujeitos históricos negros relevantes na história do país (CAMARGO, 2020).

Vivenciamos um momento de polarização política no Brasil e no mundo em que constantemente história e memória são evocadas para justificar determinadas posições, que são expostas em diferentes mídias. Se essa situação se traduz em debates por vezes acalorados nas ruas e, sobretudo, nas redes sociais, torna-se cada vez mais urgente inseri-los, de forma devidamente contextualizada e conceituada no universo escolar. Sendo assim, no caso específico do ensino 
médio $^{4}$, diante da retomada das atividades pedagógicas do CAp, foi proposto um debate sobre racismo e disputa de memória orientado pelas questões: o que é História? O que é memória? Existem disputas de memória? Quais os lugares de memória voltados às mulheres e aos homens negros no Brasil? A quem interessa o apagamento da memória de mulheres e homens negros que se destacaram na história brasileira? E quais os impactos dessa ação no presente e no futuro?

Embasada pelas leituras de Araújo (2017), Sarlo (2007), Camargo (2020) e Leal (2020), a discussão sobre a disputa de memória, relacionada à problemática do racismo no Brasil, foi acompanhada pelo debate sobre a sua perspectiva estrutural (ALMEIDA, 2016), já trabalhada em encontros anteriores, e de narrativas emocionalmente ligadas à história de vida dos alunos, de suas famílias e dos professores.

Envolvimento, paixão e sentido. A instrumentalização da consciência histórica, a partir de atividades com base na discussão sobre o racismo, possibilitou que os alunos que acompanharam a atividade se vissem imersos em um tempo histórico próximo, marcado por questões estruturais, por meio de suportes diferenciados - textos de apoio, imagens e situaçõesproblema - de modo a construir compreensões particulares. Na perspectiva proposta por Rüsen (2010), Monteiro (2003) e Wanderley (2018), procurou-se ultrapassar a prática geralmente realizada em sala de aula da transposição didática acadêmica, a partir de um processo de discussão e de construção do conhecimento do qual fizeram parte o saber erudito, os valores contemporâneos, as práticas e os problemas sociais.

Asseverando a concepção dos autores, compreende-se que o entendimento dos valores contemporâneos e dos problemas sociais vivenciados pelos discentes perpassaram a compreensão da "consciência histórica" no sentido atribuído por Rüsen (2010), como a capacidade humana de atribuir sentido à sua vida no tempo, articulando os saberes históricos obtidos dentro e fora da sala de aula, de forma a dar complexidade à compreensão das relações que se estabelecem entre as temporalidades passado, presente e futuro.

Se para os professores a organização de uma proposta pedagógica diferenciada, pautada pela abordagem conceitual, pela cultura histórica e pela consciência histórica constituiu um momento privilegiado na construção de saberes, o maior entrave para a sua completa execução foi a ausência de participação de um significativo número de alunos, considerando que a distribuição de tablets e de internet para todos os capianos que necessitavam desses recursos

\footnotetext{
${ }^{4}$ Tal proposta foi orientada pelos professores Helena Araújo, José Roberto da Silva Rodrigues e Vivian Zampa.
} 
terminou no início de setembro, mês em que a primeira fase das atividades pedagógicas remotas, nas quais se insere esse estudo de caso, tinha terminado.

Assim, uma vez experenciada as preocupações, motivações e propostas de atividades desenvolvidas pelos professores de História do CAp/UERJ, na primeira fase do ensino remoto em tempos de pandemia, urge compreender como os indivíduos que fundamentaram todo o projeto pensado, os alunos, vivenciaram esse momento. Essa questão também se apresentava para alguns dos docentes que se debruçaram para repensar o que e como ensinar história no CAp durante o período pandêmico. Um problema importante para esse grupo era conhecer algo mais sobre a subjetividade dos alunos na constituição de sentido para o "tempo excepcional" que ainda estamos vivendo e como o conhecimento histórico seria considerado na reflexão acerca desse tempo.

Enquanto professores e alunos do CAp/UERJ experenciavam uma realidade repleta de desafios e incertezas no início da pandemia, a forma como os alunos da escola produziam sentido para este período e como o relacionavam à aprendizagem histórica, seja a escolar ou a adquirida em outras instâncias produtoras de cultura histórica, pautaram ações dos participantes do projeto de pesquisa Cultura História e Ensino de História: Interseções com a História Pública - vinculado ao Laboratório de Ensino de História (CAp/UERJ) e à linha de pesquisa Narrativas Contemporâneas de História, parte do Laboratório de Estudos das Diferenças e Desigualdades (LEDDES/UERJ). Tais questões deram início à organização de um acervo de narrativas discentes, iniciado entre abril e maio de 2020, a partir do qual delineou-se a proposta de produção de vídeos curtos pelos alunos (cerca de 2 minutos), nos quais as experiências vinculadas à aprendizagem de História fossem relatadas.

\section{Narrativas discentes e aprendizado histórico-escolar}

Narrar é produzir sentido para o mundo. Assim entendidas, as narrativas constituem-se em elementos interpretativos, que possibilitam a compreensão de si e dos outros (ALMEIDA; VALENTE, 2012). Nesta dimensão, o ato de narrar é parte constitutiva do saber e do ensino de história, por materializar as experiências vividas pelos homens no tempo. É, pois, partindo destas premissas que a pesquisa buscou dar voz aos alunos da educação básica do CAp/UERJ, a fim de observar a maneira pela qual eles se relacionam com o passado humano tendo em vista orientar suas ações no presente e mesmo perspectivar futuros possíveis. 
Motivados pelas inquietações do tempo presente, potencializadas pela pandemia do novo coronavírus e pelas medidas sanitárias impostas pelo governo estadual, estes aprendizes buscaram ressignificar os dilemas que os privaram do convívio com os colegas de classe e professores, de trocas afetivas, bem como das relações sociais travadas no ambiente escolar. Através dos vídeos produzidos por estes adolescentes, buscou-se compreender o significado do aprendizado em história e os seus impactos na vida prática desses indivíduos. Ao mesmo tempo em que foi possível indagar como esses mesmos estudantes se relacionam com a cultura histórica (RÜSEN, 2010), identificando ou não outras instâncias sociais como portadoras de narrativas históricas.

Para a análise aqui apresentada foram selecionados vinte registros produzidos por alunos do CAp/UERJ, do 9ªno ao Ensino Médio, os quais compreendem a faixa etária de 14 a 18 anos $^{5}$. No vídeo os estudantes eram instados a responderem três perguntas elaboradas pelos pesquisadores no intuito de obter informações sobre a falta que a escola estava fazendo ao cotidiano do aluno, como ele relacionava temas trabalhados em sala de aula à sua compreensão da situação vivida, os usos práticos do conhecimento histórico na atualidade e, por fim, as possibilidades de aprendizagem histórica fora do ambiente escolar. As narrativas analisadas apontam para realidades distintas que se acentuaram com a pandemia de Covid-19 e que impactaram direta e indiretamente a relação destes alunos com o universo escolar. O conhecimento histórico adquirido dentro e fora de sala de aula e o lugar da história enquanto disciplina escolar que produz sentido para o tempo presente constituíram-se em elementos que nortearam a fala desses aprendizes.

Afastados da convivência escolar por conta do isolamento social, a totalidade dos relatos dos estudantes do Instituto de Aplicação afirmaram estar sentindo falta da rotina de estudos, da interação entre alunos e professores, das trocas afetivas e demais contatos interpessoais potencializados pelo espaço escolar. Para melhor compreensão, dividimos a fala dos participantes em dois momentos: antes e durante a implementação do Período Acadêmico Emergencial (PAE),

\footnotetext{
${ }^{5}$ Os vídeos foram produzidos a partir de uma proposta de extensão do projeto de pesquisa "Cultura histórica e ensino de história - interseções com a história pública”. Por meio de um questionário disponibilizado pelo Google Forms e de uma conta no Instagram, adolescentes e jovens da educação básica, compreendendo as redes particular e pública do Rio de Janeiro, encaminhavam seus vídeos respondendo as seguintes perguntas: 1) A escola está fazendo falta para você? Do que você sente falta? 2) O que estudou em História na escola está ajudando você a entender o que o mundo está vivendo? 3) Você acha que aprende história fora da escola? Se sim, esse aprendizado o tem ajudado a compreender o momento atual?
} 
com vistas a cotejar as opiniões dos discentes em relação ao processo de ensino e aprendizagem que se desenvolveu no PAE.

No primeiro momento, quando ainda não se tinha noção do porvir e a implementação do ensino remoto parecia uma realidade muito distante para a instituição e seus discentes, o medo do cancelamento das atividades escolares era uma realidade para alunos como Alpha ${ }^{6}$, um dos primeiros participantes da pesquisa. Segundo ele, a perda do "período curricular" durante a pandemia e, consequentemente, a revogação do ano letivo prejudicaria a vida dos alunos do colégio.

De maneira distinta, o estudante Beta, cujo vídeo foi encaminhado, também, no início de nossas investigações, ponderou que o sistema "AVACAp está conseguindo sustentar" o aprendizado escolar, pois como estamos no "século XXI", as informações estão ao alcance dos alunos, por meio da internet. $\mathrm{O}$ contato com conteúdos pela "metade do tempo em que (eu) aprenderia na escola" o favoreceria neste sentido, mesmo ciente de que a vida cibernética impossibilita a "mesma comunhão com as pessoas" e "todo um ambiente que se faz na escola e que faz parte" da sua "constituição como pessoa”.

Conforme os meses se passaram e o isolamento social se prolongava, a angústia e a insegurança tomaram conta da comunidade escolar, ocasionando o estresse e a exaustão de profissionais da área de educação, mas também dos discentes, de um modo geral. Por essa razão, a jovem Gama destacou as dificuldades do ensino remoto, uma vez que o "sistema educacional presencial" funciona de maneira "muito melhor, mais leve, mais participativa e mais dinâmica, e faz muito melhor até para a saúde mental dos alunos” da instituição. A falta de interação e o distanciamento das relações humanas, bem como os desafios do aprendizado fora do ambiente escolar, intensificados pelos encontros virtuais reforçaram o posicionamento destes estudantes que, por meio de suas narrativas, revelaram a preferência pelas aulas presenciais em detrimento da educação remota, explicação que se refletiu em dezessete narrativas produzidas pelos alunos durante o Período Acadêmico Emergencial.

Aluno do último ano do Ensino Médio, Delta revelou que, para além da falta que estava sentido do CAp/UERJ, vem encontrando dificuldades de concentração nos estudos, sentimento que divide com os demais colegas de série, uma vez que se submeterá a exames de admissão ao

\footnotetext{
${ }^{6}$ Visando preservar a identidade dos participantes da pesquisa, optamos por utilizar os nomes das letras do alfabeto grego.
} 
ensino superior. Destacou, ainda, que "tudo é uma questão de acessibilidade", realidade que acentuou as disparidades entre os estudantes.

O aprendizado escolar em história acumulado pelos alunos do Instituto de Aplicação, ao longo de suas vidas acadêmicas, possibilitou interpretações bastante interessantes do tempo presente, revelando o impacto do conhecimento histórico adquirido em sala de aula e suas diferentes apropriações para a vida prática destes indivíduos durante a crise sanitária. Dentro do que foi proposto como forma de abordagem para o $2^{\circ}$ ano do Ensino Médio, a estudante Épsilon considerou que através do conteúdo trabalhado no primeiro trimestre em história, foi possível "perceber, aprender as relações sociais, econômicas e políticas que se formaram ao longo do tempo e no mundo, e como essas relações humanas demonstram facilmente crise mediante uma pandemia, por exemplo".

Em se tratando de um momento de excepcionalidade, cujas atenções têm se voltado para o surto do coronavírus, muitos alunos buscaram associar o momento vivido a outros flagelos que ocorreram no passado, a exemplo da peste bubônica, da gripe espanhola e, a mais recente, gripe suína. Para o aluno Dzeta,

(...) os conhecimentos" adquiridos em outros momentos do aprendizado escolar de história "estão sendo úteis, até mesmo porque a gente está na pandemia e as coisas que a gente aprendeu sobre epidemias, como evitar, velocidade de propagação, estão impactando muito diariamente.

$\mathrm{Na}$ mesma direção, trazendo as marcas dos debates sobre a testagem de vacinas, a obrigatoriedade ou não da aplicação destes imunizantes, Eta relembrou um dos episódios da história do Rio de Janeiro, a Revolta da Vacina, como um tema estudado em sala de aula e que a faz compreender a atualidade dessas discussões.

No bojo das questões envolvendo o racismo estrutural e imbuída das ideias abordadas no ensino remoto, a jovem Teta destacou algo, que na sua opinião é "bem interessante", lembrando-se

(...) de uma coisa muito chamativa nos tempos atuais, de pandemia, que é que... é... as pessoas negras e latinas e, sabe, com descendências do gênero, sabe, elas tendem a ser o maior alvo do coronavírus e das mortes, das infecções, tendem a ser o maior alvo dessa pandemia.

A partir daí, surge a história que se aprende na escola com o questionamento: por quê? Diante deste panorama, conforme apontou a estudante, a história escolar vem em solução para explicar as injúrias raciais sofridas por estes grupos étnicos, apontando para temas tão caros como a escravidão, por exemplo, que está no cerne das desigualdades cultural e racial. 
Em dezenove dos vinte relatos produzidos pelos alunos do CAp/UERJ, foi possível verificar a construção de algum tipo de relação entre o aprendizado escolar de história a outros aprendizados resultantes de instâncias para além do ambiente escolar. Esses discentes identificam tais instâncias como portadoras de narrativas históricas e reconhecem a importância das informações veiculadas por essas mídias, embora não tenham conseguido estabelecer uma posição crítica na relação conhecimento histórico escolar - outras narrativas históricas. É o caso de Iota, que acredita que estas "complementam o saber da sala de aula". A aluna considerou, ainda, que jornais e livros são instrumentos indispensáveis para a conformação de sua consciência histórica. Resposta que se repetiu em outras três explicações.

A estudante Kappa, por seu turno, destacou que o conhecimento em história adquirido fora da escola tem ajudado bastante, pois consegue compreender "a pandemia de diferentes pontos de vista, como por diferentes classes sociais e saber como cada uma delas está passando por esse momento". Além disso, a aluna destacou que, através dessas informações, ela passou a "ter consciência dos próprios atos e ser responsável nesse momento de pandemia."

Evidentemente que, por se tratar de uma pesquisa envolvendo adolescentes e jovens, alguns dos relatos reconheceriam na indústria cultural a potência do discurso histórico, veiculado através das séries, filmes e novelas. Justificativa que apareceu em três dos vinte vídeos. É importante para o professor de história escolar perceber de que forma essas narrativas midiáticas estão produzindo significado para a relação entre passado presente e futuro para esses adolescentes. A já citada aluna Teta, por exemplo, mencionou a série “The Crown”, exibida em quatro temporadas pelo Netflix. Segundo ela, os episódios explicam bastante "sobre o que aconteceu no passado, sabe... com os reinos, no império, sabe... que... foi o que desencadeou muitas coisas hoje em dia, de mudanças que aconteceram na história”.

Apesar de toda a discussão acerca da acessibilidade aos meios digitais que permeiam a crítica ao ensino remoto nesse momento, é inegável a importância que esses suportes têm hoje em dia para a obtenção de informação, inclusive de cunho histórico. Cerca de um terço das narrativas apresentaram essas instâncias como espaços onde se aprende história. Tais apontamentos, vão de encontro às contribuições de Flávia Caimi (2014). Para autora, a cultura digital é fruto da relação entre a educação e a sociedade atual. Este tipo de vinculação ocorre de maneira constante e diversa, demandando outras formas de aprendizado que dialoguem com as demandas da contemporaneidade. Devemos considerar a atualidade deste debate, sobretudo em 
meio ao direcionamento das aulas e demais atividades remotas, e o quanto essas experiências enraizaram-se nos últimos meses.

Contudo, pôde ser constatado também que parcela dos alunos participantes permanecem atentos ao que se apreende na mídia como aprendizado. De acordo com Épsilon, a aula online não é uma "das melhores formas", uma vez que "há seus problemas". Apesar dessas ponderações a aluna revelou aprender com a nova modalidade. Lambda, por seu turno, trata com desconfiança as informações disponíveis na rede, pois "como esse conteúdo não é revisado por historiadores, são informações de procedência duvidosa", que inviabilizam o conhecimento.

Interessante perceber que alguns dos alunos que participaram da proposta buscaram relacionar de alguma forma a "validade" da informação de cunho histórico que recebiam a partir da possibilidade de esta auxiliá-los a pensar o presente, a agir no presente. Por exemplo, a visitação a lugares de memória, como museus, também portadores de narrativas históricas, foi apontado por dois estudantes como espaços para o aprendizado da disciplina. Entretanto, esses aprendizes revelaram que as informações obtidas nas exposições visitadas não os auxiliaram a pensar o tempo presente, numa atitude crítica à lógica narrativa existente nas exposições.

Outras três narrativas bastante emblemáticas indicaram que o aprendizado em história ocorre através da interação com o contexto social e político, visto que "estamos inseridos" no processo histórico, segundo Mi. Já para Gama, "a história é uma matéria que está muito presente, onde entra em vários debates e dilemas, muita coisa de política", possibilitando vislumbrar a "junção da sala da aula e da vida real na matéria.” $\mathrm{Na}$ mesma direção, a aluna $\mathrm{Ni}$ asseverou que o conhecimento de conceitos como "democracia, república, revolução, e suas causas, ajudam a identificar alguns aspectos da realidade que vivemos hoje".

Os recortes das narrativas aqui apresentadas revelam a compreensão por parte dos alunos de que seus aprendizados históricos não foram realizados apenas na escola. Pode-se perceber que muitos refletem acerca da importância de experiências vividas ou aprendidas no cotidiano no oferecimento de chaves de interpretação para o mundo real. Por outro lado, algumas das respostas vão além da identificação desse fato e discutem de alguma forma um diferencial para o aprendizado escolar de história. Embora essa inferência ainda necessite de outros cruzamentos qualitativos para uma conclusão final, não deixa de ser um aspecto importante em um contexto no qual as relações interpessoais estabelecidas na escola são pressionadas pela 
excepcionalidade da pandemia e no qual a importância da História como disciplina escolar também é posta em xeque.

\section{Uma didática da história orientada para/pela vida}

Faz algumas décadas que discussões tanto na área da Educação, quanto da História vêm produzindo mudanças conceituais na disciplina que cada vez mais ganha a denominação Didática da História ${ }^{7}$. São mudanças que ampliaram a percepção de quais seriam os seus objetos e campos de investigação. A princípio predominava a perspectiva de pensá-la apenas como uma "área de formação" pragmática e funcional, definida como um conjunto de ferramentas e práticas auxiliares na formação de professores do que hoje chamamos ensinos fundamental e médio. No presente, dependendo da perspectiva por onde se perscruta, a Didática da História assume um caráter disciplinar e científico que se debruça sobre os mistérios da transposição (ou mediação) dos conteúdos históricos acadêmicos para a realidade específica do ensino escolar de história (MONTEIRO, 2002, 2003; GABRIEL, 2003, s/d) e/ou, "dirigida por interesses práticos, indaga sobre o caráter efetivo, possível e necessário de processos de ensino aprendizagem e de processos formativos da História" (BERGMANN, 1990: p. 29).

A disciplina sai de um estado em que pouca ou nenhuma relação teria com a ciência histórica, assim como deixa de ser um campo menor nas pesquisas da Educação. Até então, seu objeto se resumiria ao ensino escolar, mesmo assim de forma meramente prática, subentendendo a escola como lugar de repetição, hierarquicamente inferior à academia. Hoje, assume status de disciplina científica pela qual disputam as áreas da Educação e da História por compreenderem as questões que a constituem como fundamentais para o entendimento da especificidade da cultura histórica escolar e do saber histórico escolar e/ou para "a formação, o conteúdo e os efeitos da consciência histórica num dado contexto histórico" (JEISMANN, 1977 apud BERGMANN, 1990: p. 29-30).

É nesse novo contexto que se enquadra a reflexão da equipe de História do CAp/UERJ que originou a intervenção didático-histórica que apresentamos nesse artigo. Profissionais de história - professores/pesquisadores - que a partir da certeza da historicidade de sua prática, de

\footnotetext{
${ }^{7}$ Como afirmam Schmidt (2006) e Urban (2009), a consolidação da disciplina didática da história passa pela constituição de um "código disciplinar", ou melhor, uma tradição configurada historicamente formando um conjunto de "ideias, valores e rotinas que definem e delineiam a função educativa da história" (SADDI, 2012: p. 212).
} 
seu fazer, dialogaram com suas fontes de referências teóricas no sentido de buscar caminhos para o processo de ensino escolar de história em um momento de rupturas em tantos sentidos da vida coletiva como o da pandemia.

O que se espera socialmente do ensino de História? pergunta-nos o professor e historiador brasileiro Luiz Fernando Cerri, em texto no qual discute a crise do ensino de história (2010) em meio a falência da capacidade de o Estado nacional afirmar seus projetos de solidariedade e identidade coletivas. Situação na qual, assevera, projetos individualistas e meritocráticos, anuladores das desigualdades recorrentes no país, tendem a sair vitoriosos.

\begin{abstract}
A recolocação - muitas vezes descontínua e atabalhoada - da questão do projeto nacional, também deixa em fragmentos os projetos de ensino de História. Os projetos públicos mais avisados para o ensino começam a fazer da individualidade, da autonomia pessoal e da identidade fragmentada em subgrupos a única alternativa aparentemente honesta de identidade para a qual o ensino de História poderia apontar, quando buscasse fugir do autoritarismo, da manipulação, da imposição artificial de um padrão de comportamento coletivo (CERRI, 2010: p. 266).
\end{abstract}

A mesma questão se fez a equipe de História do CAp/UERJ quando premida pela situação da pandemia e da exigência institucional e social do início de atividades remotas de ensino. Os resultados das intervenções apresentadas acima expressam a tentativa de romper com a solução simplista ou conservadora apontada como perigosa por Cerri.

Quando decidem partir de questões apresentadas no tempo presente, tendo em vista a mobilização da consciência histórica dos alunos, os projetos didáticos desenvolvidos "recolocam o ensino escolar de História na sua dimensão real, mergulhado na vida da sociedade que o produz" (CERRI, 2010: p. 268). A perspectiva didática na qual essas propostas estão mergulhadas ultrapassa o sentido de pensar as ações de sala de aula como meras estratégias facilitadoras da assimilação de conteúdos definidos curricularmente, vislumbrando-as como aplicação de uma teoria de aprendizagem histórica que vê esse processo como resultante não apenas do que se ensina na escola, mas, que "se dá num contexto social e histórico" amplo onde a "história [é] vivida e experimentada no seu devir de todos os dias", ou, "não experimentada nem vivida imediatamente”, mas, “transmitida cientificamente ou não” (BERGMANN, 1990: p. 30).

Colocar a perspectiva da formação da consciência histórica como um dos seus objetivos significa afirmar que, sem desconsiderar a importância que diferentes narrativas produzidas na cultura histórica contemporânea ocupam na forma como seus alunos compreendem o valor do conhecimento histórico em suas vidas, a aprendizagem histórica escolar precisa superar a ideia da mera transmissão de um rol de conteúdos pré-estabelecidos e, também em um momento 
excepcionalmente traumático como o que vivenciamos com a pandemia de Covid-19, constituirse "como esforço de orientação ou reorientação das formas de produção de sentido dos outros, a ser regulado cientifica e socialmente, evitando abusos políticos, bem como neutralismos esterilizantes" (CERRI, 2010: p. 270).

A preocupação com a identidade de quem está recebendo a ação didática é latente na proposta da produção de narrativas sejam orais ou por meio de vídeos. Por trás dessas ações está a certeza de que não se ensina se não se conhece as ideias históricas que os sujeitos da aprendizagem carregam para a sala de aula.

Da mesma forma, a preocupação em apropriar-se de forma crítica do noticiário que expõe o racismo latente na ação policial que levou à morte do cidadão afro-americano George Floyd e sua repercussão social pelo mundo, inclusive no Brasil, cruzando esse acontecimento com análises e conteúdos sobre o escravismo no continente americano, preconiza a preocupação de que é objetivo do ensino escolar de história se utilizar da reflexão metódica histórica para dar conta da prevenção de "identidades não-razoáveis", ou seja, marcadas pela radicalização "do que é, na essência, toda identidade: delimitar e excluir", levando tais identidades a se tornarem destrutivas, chegando a negar o direito de existência de outras identidades.

\footnotetext{
(...) é uma das exigências da Didática da História que o ensino de História tenha que ser o lugar onde se reflita de maneira crítica sobre as identidades próprias e alheias. A necessidade de uma atitude autocrítica é tanto mais urgente quanto o ensino da história mesmo faz parte da cultura histórica de uma sociedade; além disso, 'culturas são ofertas de identidades' (A. Assmann) e por onde o ensino de história se coloca dentro destas ofertas. (GARCIA, 1998 apud CERRI, 2010: p. 271).
}

Em essência, o que a proposta didática apresentada visa resgatar é o sentido social de historiar e de ensinar. Como um território fronteiriço (CERRI, 2004/2005), lugar de fronteira (MONTEIRO, 2011) ou entrelugar (WANDERLEY, 2020), o que os estudos contemporâneos nos lembram é que o trabalho no campo do ensino de história necessita dialogar incessantemente com reflexões teóricas oriundas de áreas científicas diferenciadas sem esquecer de manter o ouvido atento aos saberes e narrativas oriundos da cultura histórica contemporânea da qual ela mesma participa.

O processo amalgamado pelo ensino-aprendizagem da história escolar é parte dessa cultura e ao mesmo tempo seu resultado. Nesse vai e vem entre parte e todo mora a sua especificidade e também reside a sua força - a profundidade de seu hibridismo e a polissemia de seu significado. 


\section{Referências}

ALMEIDA, S. L. Marxismo e a questão racial. Coluna de apresentação do Dossiê "Marxismo e questão racial". Revista Margem Esquerda, São Paulo, 27, 2016. Disponível em: <https://blogdaboitempo.com.br/2016/12/14/marxismo-e-a-questao-racial/>. Acesso em: 20 jul. 2020.

ARAÚjO, Helena Maria Marques. Educar através da(s) Memória(s). E-Mosaicos, Rio de Janeiro, v. 6 , n. 12, p. 221-222, agosto de 2017. Disponível em:

<file://C:/Users/vivia/OneDrive/Documentos/Educar\%20atrav\%C3\%A9s\%20de\%20mem \%C3\%B3rias\%20-\%20Helena\%20Ara\%C3\%BAjo.pdf>. Acesso em: 15 jul. de 2020.

BERGMANN, Klaus. A História na reflexão didática. Revista Brasileira de História, São Paulo, v. 9, nº 19, p. 29-42, set.1989/fev.1990.

BITTENCOURT, Circe Fernandes. Abordagens Históricas Sobre a História Escolar. Educação $\mathcal{E}$ Realidade, Porto Alegre, v. 36, n.1, p. 83-104, jan./abr., 2011. Disponível em: <file://C:/Users/vivia/OneDrive/Documentos/Unirio\%20-\%20EAD/2019.2/15136-717072-PB.pdf>. Acesso em: 12 jan. 2019.

CAMARGO, Lucas. Apagamento: Sérgio Camargo ordenou a remoção de biografias do site da Fundação Palmares. FÓRUM. Disponível em: $<$ https://revistaforum.com.br/politica/apagamento-sergio-camargo-ordenou-a-remocao-debiografias-do-site-da-fundacao-palmares/>. Acesso em: 20 jun. 2020.

CERRI, Luiz Fernando. Ensino de História: fronteiras interdisciplinares, avanços e problemas. Cadernos de História, Uberlândia, vol. 12/13 n 1, p. 7-21, 2004/2005.

. Ensino de História e concepções historiográficas. Espaço Plural, Cascavél, Ano X . n. 20. p. 149-154, 1० Semestre 2009.

Didática da História: uma leitura teórica sobre a História na prática. Revista de História Regional, Ponta Grossa, 15(2), p. 264-278, inverno 2010.

CRUZ, Cacilda Fontes. Relato de experiência: ensinar História para alunos jovens e adultos pela plataforma CEJA num contexto de pandemia e de isolamento social no primeiro semestre de 2020. Anais do XIX Encontro de História da Anpuh-Rio. Rio de Janeiro, 21 a 25 de setembro de 2020 .

COSTARD, Larissa et al. Carta aos estudantes e responsáveis do CAp-UERJ, 2020. (Manuscrito)

DIAS, Érika; PINTO, Fátima da Cunha Ferreira. A Educação e a Covid-19. Aval. Pol. Públ. Educ., Rio de Janeiro, vol. 28, no 108, Jul./Sept. 2020, Epub July 06, 2020. Disponível em: $<$ https://www.scielo.br/scielo.php?script=sci arttext\&pid=S0104-40362020000300545>. Acesso em: 15 out. 2020. 
FERREIRA, Marieta de Moraes. História do tempo presente: desafios. Cultura Vozes, Petrópolis, v. 94, no 3, p.111-124, maio/jun., 2000.

GABRIEL, Carmem Teresa. Um objeto de ensino chamado História. A disciplina de História nas tramas da didatização. 2003. Tese (Doutorado em Educação) - Programa de Pós-graduação em Educação da PUC-Rio, Rio de Janeiro, 2003.

Usos e abusos de transposição didática. Trabalho apresentado no IV Seminário Perspectivas do Ensino de História, Ouro Preto, 2001. Disponível em: <http://www.ichs.ufop.br/perspectivas/anais/GT0509.htm>. Acesso em: 2 fev. 2020.

GUMBRECHT, H. U. Depois de "Depois de aprender com a história", o que fazer com o passado? Transcrição de Camila Braga. In: NICOLAZZI, F.; MOLLO, H. M.; ARAUJO, V. L. (Orgs.). Aprender com a história? O passado e o futuro de uma questão. Rio de Janeiro: Ed. FGV, 2011.

LEAL, Bruno. Especialistas comentam derrubadas de monumentos e estátuas pelo mundo. Café História. Disponível em: <https://www.cafehistoria.com.br/especialistas-comentam-derrubadade-estatuas-pelo-mundo/>. Acesso em: 20 jun. 2020.

LIMA, Maria. Consciência histórica e educação histórica: diferentes noções, muitos caminhos. In: MAGALHÃES, Marcelo et al. Ensino de história: usos do passado, memória e mídia. Rio de Janeiro: Ed. FGV, 2014.

MONTEIRO, Ana Maria Ferreira da Costa. Ensino de História: entre saberes e práticas. 2002. Tese (Doutorado em Educação) - Programa de Pós-graduação em Educação da PUC-Rrio, Rio de Janeiro, 2002.

. Ensino de história: algumas configurações do saber escolar. História e Ensino, Londrina, vol. 9, p. 9-36, 2003.

Ensino de História: saberes em lugar de fronteira. Educação $\mathcal{E}$ Sociedade, Porto Alegre, v. 36, nº 1, p. 191-211, jan.abril/2011.

PINHA, Daniel; SOTENOS, Abner. E se George Floyd fosse brasileiro? Site Jornalistas Livres. 2020. Disponível em: < https://ctb.org.br/noticias/opiniao/e-se-george-floyd-fosse-brasileiro/>. Acesso em: 10 fev. 2021.

SANTOS JUNIOR, Irapoan Bertholdo dos. Percepção de alunos e professores da Seeduc/RJ sobre o ensino on-line de caráter emergencial durante a pandemia. Educação Pública, agosto de 2020. Disponível em: <https://educacaopublica.cecierj.edu.br/artigos/20/30/percepcao-dealunos-e-professores-da-seeducrj-sobre-o-ensino-ion-linei-de-carater-emergencial-durante-apandemia>. Acesso em: 19 out. 2020.

RÜSEN, Jörn. "¿Qué es la cultura histórica? Reflexiones sobre una nueva manera de abordar la historia". Culturahistórica. [Versión castellana inédita del texto original alemán en K. Füssmann, 
H.T. Grütter y J. Rüsen, eds. (1994). Historische Faszination. Geschichtskultur heute. Keulen, Weimar y Wenen: Böhlau, pp. 3-26]. Disponível em: 〈http://www.culturahistorica.es/ruesen/cultura historica.pdf >. Acesso em: 15 jun. 2020.

Como dar sentido ao passado: questões relevantes de meta-história. História da historiografia, Ouro Preto, n. 2, p. 163-209, mar. 2009.

. Razão histórica: teoria da história: fundamentos da ciência histórica. Brasília: Editora $\mathrm{UNB}, 2010$.

. Didática da História: passado, presente e perspectivas a partir do caso alemão. In: SCHMIDT, Maria Auxiliadora; BARCA, Isabel; MARTINS, Estevão de Rezende (orgs.). Jörn Rüsen e o ensino de história. Curitiba: Ed. UFPR, 2010a, p. 23-40.

SADDI, Rafael. O parafuso da didática da história: o objeto de pesquisa e o campo de investigação de uma didática da história ampliada. Acta Scientiarum, Maringá, v. 34, nº 2, p. 211 . 220, jul.-dez. 2012.

SARLO, Beatriz. Tempo passado: cultura da memória e guinada subjetiva. Tradução de Rosa Freire d'Aguiar. São Paulo: Companhia das Letras; Belo Horizonte: UFMG, 2007. (Capítulo 1) Disponível em: <http://www.legh.cfh.ufsc.br/files/2015/04/SARLO-Beatriz.-TempoPassado.pdf $>$. Acesso em: 15 jul. 2020.

SCHNEIDERS, Carlise. O ensino de História no ensino fundamental II em um contexto pandêmico: relato de experiência. In: PALÚ, Janete; SCHÜTZ, Jenerton Arlan; MAYER, Leandro (Orgs.). Desafios da educação em tempos de pandemia. Cruz alta: Ilustração, 2020, p. 205216.

WANDERLEY, Sonia. Didática da história escolar: um debate sobre o caráter público da história ensinada. In: ALMEIDA, Juliene Rabêlo de; MENESES, Sônia (Org.). História pública em debate: Patrimônio, educação e mediações do passado. São Paulo: Letra e Voz, 2018. p. 95-108.

O entrelugar do aprendizado escolar de História: uma perspectiva de História Pública. Revista História Hoje, v. 9, n 18, p. 125-144, 2020.

\section{Sobre as autoras:}

Giselle Pereira Nicolau: Possui doutorado em História Contemporânea pela Universidade Federal Fluminense (2018), com bolsa sanduíche na École de Hautes Études en Sciences Sociales (2017). Atua nas áreas de Brasil Império e República, Migrações, História Política, Biografia e Historiografia. Além disso, a pesquisadora/professora possui mestrado (2012) e graduação (2009) em História pela Universidade do Estado do Rio de Janeiro, onde desenvolveu pesquisas que contemplavam temas sobre: Cultura Política, os Usos do Biográfico na Escrita da História, Teatro, Imigração Urbana para o Rio de Janeiro, em especial a francesa, e Ensino de História. 
Vivian Zampa: Possui Graduação em História pela Universidade Federal Fluminense (1999), Mestrado em História Política pela Universidade do Estado do Rio de Janeiro (2003) e Doutorado em História Política pela mesma Instituição (2014). Tem experiência em pesquisa em diferentes Instituições do Rio de Janeiro, atuando principalmente nos temas: Polícia Militar, Segurança Pública, Ditadura Civil Militar e Ensino de História. Atualmente é Professora do Curso de Licenciatura em História da Universidade do Estado do Rio de Janeiro e do Cap-UERJ, coordenadora da disciplina História do Brasil IV (EAD) da Universidade Federal do Estado do Rio de Janeiro e professora do Programa de Pós-graduação em História da Universidade Salgado de Oliveira, vinculado à linha de pesquisa "Política, Movimentos Sociais e Memória".

Sonia Maria Wanderley: Possui graduação em História pela Universidade do Estado do Rio de Janeiro (1983), graduação em Comunicação pela Universidade Federal do Rio de Janeiro (1979), mestrado em História pela Universidade Federal Fluminense (1995) e doutorado em História pela Universidade Federal Fluminense (2005). Atualmente é professora associada da Universidade do Estado do Rio de Janeiro. Tem experiência na área de História, com ênfase em História do Brasil República, atuando principalmente nos seguintes temas: ensino de história, didática da história, história pública, história social da Tv no Brasil.

Artigo recebido para publicação em: 30 de setembro de 2021.

Artigo aprovado para publicação em: 03 de dezembro de 2021.

\section{Como citar:}

NICOLAU, Giselle Pereira; ZAMPA, Vivian Cristina; WANDERLEY, Sonia Maria. Aprendizagem escolar de História em tempos de pandemia no Cap-UERJ: um olhar didáticohistórico sobre o tempo presente. Revista Transversos. Dossiê: $\mathrm{O}$ futuro do passado: Desafios para o Ensino da História nas escolas numa perspectiva global. Rio de Janeiro, nº. 23, 2021. pp. 209. $229 . \quad$ Disponível em: <https://www.epublicacoes.uerj.br/index.php/transversos/article/view/62746>. ISSN 2179-7528. DOI: $10.12957 /$ transversos.2021.62746

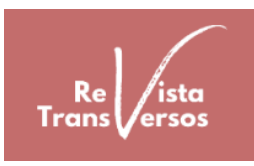

